\title{
Kolorektal kanser tanı ve tedavisinde önemli bir problem: Obstrüksiyon
}

\section{A predominant problem in the diagnosis and treatment of colorectal cancer: Obstruction}

\section{(D) Sami ÇİÇI $I^{1}$, (D) Nergiz EKMEN²}

Basaksehir Cam-Sakura Sehir Hastanesi, ${ }^{1}$ Gastroenteroloji Kliniği, Istanbul

Gazi Üniversitesi Tip Fakültesi, ${ }^{2}$ Gastroenteroloji Bilim Dall, Ankara

\begin{abstract}
Giris ve Amaç: Kolorektal kanserler günümüzde hala en sik ölüm nedenleri arasındadır. Kolorektal kanserlerde mortalite ve morbidite başlangıç kolonoskopisi ve tespit edilen lezyonlar ile doğrudan ilișkilidir. Obstrükte kolorektal kanserlerde başlangıçta yeterli inceleme her zaman önemli bir sorun olmustur. Biz obstrüksiyon tespit edilen kolorektal kanser oranını ve bu hastalara olan yaklaşımı ele almaya çalıştık. Gereç ve Yöntem: Ocak 2015- Arallk 2019 tarihleri arasında Istanbul S.B.Ü. Kanuni Sultan Süleyman Eğitim ve Araştırma Hastanesinde yapılan 10326 kolonoskopi işlemi hasta dosyalarnndan ve elektronik data üzerinden kolon kanseri yönünden retrospektif olarak analiz edildi. Çalışmada hastaların yaş, cinsiyet ve kolonoskopi sonuçları barsak temizliği, obstrüksiyon varlı̆̆ı, tümör lokalizasyonu, patolojik tanıları yönünden analiz edilerek kayıt edildi. Bulgular: 10326 hasta dosyas taranarak 145 (\%62.2) erkek ve 88 (\%37.8) kadın olmak üzere 233 kolon kanseri tanısı konan hasta çalıșmaya dâhil edildi. Calıșmamızda kolorektal kanser görülme sıklı̆ı \%0.02 olarak tespit edildi. Tanı alan hastalarda en sık endikasyon \%28.8 $(n=67)$ ile rektal kanama iken en sik lokalizasyon bölgesi \%44.6 (n=104) ile rektum olarak tespit edilmiștir. Obstrüksiyona göre tümör lokalizasyonları incelendiğinde \%69.9 (n=51) ile en yüksek obstrüksiyon tespit edilen bölge rektosigmoid bölge olmuştur. Sonuç: Kolon kanseri en sık lokalizasyon olarak rektosigmoid bölgeyi tutmakta ve bu bölgede belirgin oranda obstrüksiyona neden olmaktadır. Obstrüksiyon nedeni ile tanı anında kolonoskopik inceleme yeterli derecede yapılamamakta, bu da senkron lezyonların tespitini azaltmaktadır. Biz bu tür hastalarda preoperatif bilgisayarlı tomografik kolonografinin uygun olabileceğini hatırlatmaktayız.
\end{abstract}

Anahtar kelimeler: Kolorektal kanser, lokalizasyon, obstrüksiyon

\section{GİRİs}

Kolorektal kanser (KRK), dünya çapında önde gelen mortalite ve morbidite nedenlerinden biridir ve bu nedenle önemli bir halk sağlığı sorununu temsil etmektedir. Dünya çapında üçüncü en yaygin kanserdir (akciğer ve meme tümörlerini takiben) ve onkolojik kaynaklı ölümlerin en yaygın dördüncü nedenidir (1). KRK'li hastaların hem tanı hem de tedavi süreçlerinde titizlikle incelenmesi ve tedavilerinin planlanmasl, morbidite ve mortalite üzerine önemli etkilerinin olduğu bilinmektedir (2). Kolonoskopi işlemi ile kolon kanserinin erken tanısı ve premalign lezyonların çıkarılması ölüm oranlarını azalmaktadır (3). Çeşitli nedenler ile bazen bu inceleme yeterli derecede yapılamamaktadır. Örneğin yetersiz bağırsak temizliğinin; kolonoskopi işlemini tüm yönleri ile etkilemekle birlikte, özellikle adenom ve ileri adenomların saptanma
Background and Aims: Colorectal cancers remain among the most common causes of death today. The mortality and morbidity rates of colorectal cancers are directly related to initial colonoscopy and lesion detection. Insufficient colonoscopic examination has always been an important problem in colorectal cancers diagnosed with obstruction. We examine the rates of obstruction and how to approach to these patients. Materials and Method: $A$ total of 10326 colonoscopy procedures performed in Istanbul S.B.U. Kanuni Sultan Suleyman Training and Research Hospital between January 2015 and December 2019 were retrospectively analyzed in terms of colon cancer from patient files and electronic data. In this study, the age, sex, and colonoscopy results of the patients were analyzed in terms of bowel cleansing, presence of obstruction, tumor localization, and pathological diagnoses. Results: A total of 10326 files were scanned, and 233 patients with colorectal cancer, $145(62.2 \%)$ males and 88 (37.8\%) females, were included in the study. The incidence of colorectal cancer was $0.02 \%$. The most common indication was rectal bleeding $(28.8 \%, n=67)$, and the most common localization region was the rectum $(44.6 \%, n=104)$. When the tumor localizations were examined according to obstruction, the region with the highest obstruction was the rectosigmoid region, with a frequency of $69.9 \%(n=51)$. Conclusion: Colorectal cancer most commonly involves localization in the rectosigmoid region and is a significant cause of obstruction in this area. Colonoscopic examinations cannot be performed adequately at the time of diagnosis because of obstruction, which reduces the detection rate of synchronous lesions. Therefore, we considered that preoperative computed tomography colonography may be appropriate in such patients.

Key words: Colorectal cancer, localization, obstruction

oranlarını anlamlı derecede düşürdüğü tespit edilmiştir (4). Başlangıç kolonoskopik incelemenin kalitesi ve tespit edilen adenom oranı ile KRK'den ölümler arasında direkt bir ilişki olduğu belirtilmiştir (5). Tüm bu nedenlerden dolayı KRK'li hastalarda endoskopik sürveyans büyük öneme sahiptir. Endoskopik sürveyans ile metakron kanserlerin ve intralüminal nüks kanserlerin erken tespiti hedeflenmektedir (6). Senkron kanser tespitinde zaman zaman çeşitli nedenler ile zorlanılmaktadır, yetersiz bağırsak temizliği dışında, hem yetersiz temizliğe neden olması, hem de endoskopik incelemenin mümkün olamadığı kitleye bağlı darlık, bizim ve hasta açısından önemli sorunlara neden olabilmekte ve hastalığın prognozu üzerine kötü etkileri olabilmektedir $(5,6)$. 
$\mathrm{Bu}$ çalışmada KRK tanısı konulan hastalarda darlık nedeni ile lezyon proksimalinin endoskopik olarak incelenemediği hastaların tespiti ve bu hastalara olan yaklaşımı ele almaya çalıştık.

\section{GEREC ve YÖNTEM}

Ocak 2015- Aralık 2019 tarihleri arasında Istanbul S.B.Ü. Kanuni Sultan Süleyman Eğitim ve Araştırma Hastanesinde yapılan kolonoskopi işlemleri hasta dosyalarından ve elektronik veri üzerinden KRK yönünden geriye dönük olarak analiz edildi. Kolonoskopi ve biyopsi ile KRK tanısı konulan hastalar çalışmaya dahil edildi. 18 yaş altı ve patolojik olarak KRK tanısı doğrulanmamış hastalar çalışmaya dâhil edilmedi. Çalışmada hastaların yaş, cinsiyet ve kolonoskopi sonuçları barsak temizliği, obstrüksiyon varlı̆ğ, tümör lokalizasyonu patolojik tanıları yönünden analiz edildi. Tümör lokalizasyonları; rektum, sigmoid kolon, inen kolon, transvers kolon, hepatik fleksura, çıkan kolon ve çekum olarak kayıt edildi. Çalışmamız Istanbul S.B.Ü. Kanuni Sultan Süleyman Eğitim ve Araștırma Hastanesi Klinik Araștırmalar Etik Kurulunun 10.09.208 tarih ve 2018-07 numaralı kararı ile yapılmıștır.

\section{İstatiksel Analiz}

Verilerin analizi Statistical Package for the Social Sciences (22 SPSS, Inc, Chicago IL, USA) kullanılarak yapılmıștır. Tanımlayıcı istatistikler kısmında kategorik değişkenler sayı, yüzde verilerek, sürekli değişkenler ise ortalamaıstandart sapma (SS) ve ortanca (minimum- maksimum) ile sunulmuștur. Karşılaştırmalı veriler ortalama \pm standart hata olarak gösterilmiştir. Sürekli değişkenlerin normal dağllıma uygunluğu görsel (histogram ve olasılık grafikleri) ve analitik yöntemler Kolmogorov-Smirnov/Shapiro-Wilk testleri kullanılarak değerlendirilmiştir. Bağımsız gruplar arasında sürekli değişkenler için independent sample test ve kategorik değişkenler için yapılan karşılaştırma analizinde Pearson ki-kare ( $\chi 2)$ testi kullanılmıştır. Bu çalışmada istatistik anlamlılık düzeyi $\mathrm{p}$ $<0.05$ olarak kabul edilmiștir.

\section{BULGULAR}

5030 erkek, 5296 kadın olmak üzere 10326 hasta dosyası tarandı. Toplam 257 KRK tanılı hasta tespit edildi, ancak kolonoskopi raporları ve dosya verileri yetersiz olan 24 hasta çalışmaya alınmadı. 145 (\%62.2) erkek, 88 (\%37.8) kadın olmak üzere 233 kolon kanseri tanısı konan hasta çalışmaya

\section{Tablo 1. Demografik veriler}

\begin{tabular}{|c|c|c|c|c|}
\hline $\begin{array}{r}\text { Cinsiyet } \\
\text { Erkek } \\
\text { Kadın }\end{array}$ & $\begin{array}{l}(\%)^{*} \\
62.2 \\
37.8\end{array}$ & Yaş (yıl) & $\begin{array}{c}\text { Ort } \pm \text { Ss } \\
65.02 \pm 11.99 \\
67.40 \pm 15.13\end{array}$ & $\begin{array}{c}\mathbf{P a} \\
0.184\end{array}$ \\
\hline $\begin{array}{l}\text { Endikasyon } \\
\text { Rektal kanama } \\
\text { Bilinmiyor } \\
\text { Anemi } \\
\text { İshal } \\
\text { Malignite tetkik } \\
\text { Karın ağrısı } \\
\text { GGK+ } \\
\text { Metastatik hastalık } \\
\text { Kabızlık } \\
\text { Bağırsak alışkanlığında değişiklik }\end{array}$ & & $\begin{array}{c}(\mathbf{n}) \\
67 \\
25 \\
54 \\
24 \\
12 \\
6 \\
19 \\
7 \\
9 \\
10\end{array}$ & $\begin{array}{l}(\%)^{*} \\
28.8 \\
10.7 \\
23.2 \\
10.3 \\
5.2 \\
2.6 \\
8.2 \\
3.0 \\
3.9 \\
4.3\end{array}$ & \\
\hline $\begin{array}{l}\text { Temizlik } \\
\text { Yeterli } \\
\text { Yetersiz }\end{array}$ & & $\begin{array}{l}(\mathbf{n}) \\
177 \\
56\end{array}$ & $\begin{array}{l}(\%)^{*} \\
76.0 \\
24.0\end{array}$ & \\
\hline $\begin{array}{l}\text { Lokalizasyon } \\
\text { Rektum } \\
\text { Sigmoid kolon } \\
\text { Inen kolon } \\
\text { Transvers kolon } \\
\text { Hepatik fleksura } \\
\text { Çıkan kolon } \\
\text { Çekum }\end{array}$ & & $\begin{array}{l}(\mathbf{n}) \\
104 \\
55 \\
15 \\
18 \\
10 \\
20 \\
11\end{array}$ & $\begin{array}{c}(\%)^{*} \\
44.6 \\
23.6 \\
6.4 \\
7.7 \\
4.3 \\
8.6 \\
4.7\end{array}$ & \\
\hline
\end{tabular}

*:satır yüzdesi; a :independent sample t test; GGK+: Gaitada gizli kan pozitifliği 
dâhil edildi. Erkeklerde yaş ortalaması $65.02 \pm 11.99$ yll, kadınlarda yaş ortalaması $67.40 \pm 15.13$ yll olup aralarında istatistiksel olarak anlamlı farklılık saptanmadı ( $\mathrm{p}=0.184)$.

Çalışmamızda KRK görülme sıklı̆̆ı \%0.02 olarak tespit edildi. Tanı alan hastalarda en sık endikasyon \%28.8 ( $n=67$ ) ile rektal kanama iken, en sık lokalizasyon bölgesi \%44.6 ( $\mathrm{n}=104)$ ile rektum olarak tespit edilmiştir (Tablo 1). Adenokarsinom \%97.9 ( $\mathrm{n}=228$ ) oranında en sik saptanan patolojik tanı olurken p53 >\%50 pozitifliği 77 hastada (\%33) ve ki-67 >\%50 pozitifliği 31 hastada (\%13.3) tespit edilmiştir (Tablo 2). Obstrüksiyona göre tümör lokalizasyonları incelendiğinde, rektumda \%29.8 ( $\mathrm{n}=31)$ ve sigmoid kolonda \%36.4 ( $\mathrm{n}=20)$ ile en yüksek obstrüksiyon tespit edilen bölge rektosigmoid bölge (\%69.9, n=51) olmuştur (Tablo 3). Obstrüksiyon varlığı yönünden lokalizasyona göre yapılan incelemede istatistiksel olarak anlamlı farklılık saptanmamıștır.

\section{Tablo 2. Patoloji}

\begin{tabular}{|ccc}
\hline Patolojik Tanı & N & \%* \\
Adenokarsinom & 228 & 97.9 \\
Taşlı yüzük hücreli tümör & 2 & 0.9 \\
Nöroendokrin tümör & 1 & 0.4 \\
Lenfoma & 1 & 0.4 \\
Malign epielyal tümör & 1 & 0.4 \\
P53 & & \\
Negatif & 15 & 6.4 \\
>\%50 pozitif & 77 & 33.0 \\
Zayif pozitif & 14 & 6.0 \\
Bilinmiyor & 127 & 54.5 \\
Ki-67 & & \\
\%50> & 31 & 13.3 \\
Zaylf & 8 & 3.4 \\
Bilinmiyor & 194 & 83.3 \\
\hline
\end{tabular}

*:satır yüzdesi

Tablo 3. Lokalizasyona göre obstrüksiyon durumu

\begin{tabular}{|lccc|}
\hline \multicolumn{3}{c}{ Obstrüksiyon Durumu } \\
& Var* & Yok* & P \\
\hline Rektum & $31(29.8)$ & $73(70.2)$ & AUD \\
\hline Sigmoid kolon & $20(36.4)$ & $35(63.6)$ & \\
\hline Inen kolon & $8(11.0)$ & $7(4.4)$ & \\
\hline Transvers kolon & $5(6.8)$ & $13(8.1)$ \\
\hline Hepatik fleksura & $5(6.8)$ & $5(3.1)$ \\
\hline Çıan kolon & $4(5.5)$ & $16(10)$ \\
\hline Çekum & $0(0.0)$ & $11(4.7)$ \\
\hline Total & $73(31.3)$ & $160(68.7)$ \\
\hline
\end{tabular}

Pearson Ki- kare analizi kullanılmıștır. *:satır yüzdesi. AUD: Analize uygun değil.

\section{TARTISSMA}

Kolorektal kanser nedeniyle opere olan hastalar genel popülasyona göre 1.5-2 kat arasında artmıs metakron kanser riskine sahiplerdir ve bu risk ilk üç yllda en yüksek seviyededir (6). Takip sırasinda tespit edilen kolorektal kanserlerin büyük çoğunluğunun kaçırılmış lezyonlar ve yetersiz polip eksizyonu nedeniyle olduğu (7) ve bunların sıklıkla proksimal kolondan kaynaklandığı belirtilmektedir (8). Bir kısım epidemiyolojik çalışmada, KRK hastalarının \%4.5'inde senkron KRK olduğu (9) ve hastaların yaklaşık \%2l'inde senkron adenom olduğu belirtilmiştir (10). Senkron KRK'in metakron KRK riskinde artışla ilişkili olduğu (6) ayrıca senkron ileri adenomların, artmış metakron KRK olasılığı ile ilişkili olduğu da bildirilmişstir (11).

Tüm bu nedenler ile hem senkron hem de metakron kanserlerin yeterli ve etkin olarak değerlendirilmesi kaçınılmaz görünmektedir. Bizim de üzerinde durduğumuz ve belirtmek istediğimiz, tanı anında obstrüksiyon ile başvuran hastaların değerlendirilmesindeki sorunlardır. Özellikle proksimal kolonun incelenmesinin gerekliliği önemli bir tartışma konusu haline gelmiştir. Literatüre baktı̆̆ımızda KRK'de \%15-20 oranında obstrüksiyon görülebildiği belirtilmektedir (12). 234 obstrükte KRK'in alındığı bir çalışmada obstrükte kitlelerin büyük çoğunluğunun sol kolonda ve özellikle de rektosigmoid bölgede olduğu tespit edilmiştir (13). Ülkemizde yapılmış olan bir çalışmada KRK'in \%77'sinin sol kolonda ve bu olguların \%66.l'inde rektosigmoid bölgede yerleşimli olduğu tespit edilmiş ancak obstrükte kitle sayısı hakkında bilgi verilmemiştir (14).

Obstrüksiyon nedeniyle yeterli inceleme yapilamayan hastalarda Amerikan Gastroenteroloji Derneği (AGA) postoperatif kolonoskopiyi daha erkene çekerek 3 ile 6 ay içerinde yapılmasını önermektedir (15). Avrupa Gastrointestinal Endoskopi Derneği (ESGE) de benzer şekilde postoperatif en geç 6 ay içerisinde kolonoskopinin yapılmasını önermektedir (16).

Özellikle laparoskopik kolektomi tekniklerinin günümüzde giderek yaygınlaşması, tümör bölgesi ve diğer kolon segmentlerinin palpasyon imkânının olmaması, proksimal kolon segmentlerinin incelenmesini bir kat daha önemli kılmıştır. Proksimal kolonun incelenmesi için intraoperatif kolonoskopi bir yöntem olarak kullanılabilir (17) ancak teknik olarak bu imkâna ulaşmadaki güçlükler nedeniyle pratik olarak kullanımda zorluklar bulunmaktadır.

Obstrüksiyonu bulunan hastaların değerlendirilmesinde başka bir yöntem olarak bilgisayarlı tomografi kolonografi (BTK) tanı ve takip için bir seçenek olarak kabul edilmiştir (18). 284 obstrükte kolon kanserini içeren bir vaka serisinde BTK kullanılarak yüksek sensitivite ile proksimal senkronize kolorektal patolojiler tespit edilebilmiştir (19). BTK işleminde özellikle belirgin obstrüksiyon durumlarında artmıs perforasyon riskinin olabileceği unutulmamalıdır. 
AGA tam kolonoskopiyi önleyen obstrüktif KRK hastalarında, senkron neoplazmaları dışlamak için en iyi alternatif olarak BTK'yı önermektedir (20). ESGE de aynı şekilde obstrüksiyon gibi nedenlerle tam kolonoskopisi yapilamayan hastalarda preoperatif BTK önermektedir (21).

Bizim çalışmamızda 233 hastanın \%31.3'ünde (n=73) obstrüksiyon tespit edildi. Rektosigmoid bölgede tümör tespit edilen hasta oranı \%68.2 ( $\mathrm{n}=159)$ olup literatür ile uyumluydu (22). Bu bölgedeki kitlelerin de \%32'sinde ( $\mathrm{n}=51)$ obstrüksiyon tespit edildiği ve bu nedenle de proksimal kolon segmentlerinin incelenememiş olduğu görüldü. Yine obstrüksiyonun da büyük katkısının olduğu yetersiz kolon temizliği hastaların \%24'ünde $(n=56)$ izlenmiștir. Obstrüksiyon ve/veya kirlilik nedeniyle toplamda hastaların \%45.9'unun $(\mathrm{n}=107)$ proksimal kolon segmentlerinin yeterince incelenememiş olduğu görülmüştür.

\section{KAYNAKLAR}

1. Torre LA, Bray F, Siegel RL, et al. Global cancer statistics, 2012. CA Cancer J Clin 2015;65:87-108

2. Sulz MC, Kröger A, Prakash M, et al. Meta-analysis of the effect of bowel preparation on adenoma detection: early adenomas affected stronger than advanced adenomas. PLoS One 2016;11:e0154149.

3. Baxter NN, Warren JL, Barrett MJ, Stukel TA, Doria-Rose VP. Association between colonoscopy and colorectal cancer mortality in a US cohort according to site of cancer and colonoscopist specialty. J Clin Oncol 2012;3021:2664-9

4. Clark BT, Rustagi T, Laine L. What level of bowel prep quality requires early repeat colonoscopy: systematic review and meta-analysis of the impact of preparation quality on adenoma detection rate. Am J Gastroenterol 2014;109:1714-23

5. Corley DA, Jensen CD, Marks AR, et al. Adenoma detection rate and risk of colorectal cancer and death. N Engl J Med 2014;370:1298-306

6. Mulder SA, Kranse R, Damhuis RA, et al. The incidence and risk factors of metachronous colorectal cancer: an indication for follow-up. Dis Colon Rectum 2012:55:522-31.

7. Kahi CJ, Anderson JC, Rex DK. Screening and surveillance for colorectal cancer: state of the art. Gastrointest Endosc 2013;77:335-50.

8. Liu L, Lemmens VE, De Hingh IH, et al. Second primary cancers in subsites of colon and rectum in patients with previous colorectal cancer. Dis Colon Rectum 2013;56:158-68.

9. Mulder SA, Kranse R, Damhuis RA, et al. Prevalence and prognosis of synchronous colorectal cancer: a Dutch population-based study. Cancer Epidemiol 2011;35:442-7.

10. Bouvier AM, Latournerie M, Jooste $\mathrm{V}$, et al. The lifelong risk of metachronous colorectal cancer justifies long-term colonoscopic followup. Eur J Cancer 2008;44:522-7.

11. Marques-Antunes J, Libanio D, Goncalves $\mathrm{P}$, et al. Incidence and predictors of adenoma after surgery for colorectal cancer. Eur J Gastroenterol Hepatol 2017;29:932-8.

12. Gaiani F, Patrizi F, Sobhani I, de'Angelis GL. Principles of colonoscopy for colorectal cancer emergency. In: de'Angelis N, Di Saverio S, Brunett F. (eds). Emergency Surgical Management of Colorectal Cancer. Hot Topics in Acute Care Surgery and Trauma. Springer, Cham; 2019:69-80.
$\mathrm{Bu}$ çalışmanın sınırlayıcı özellikleri retrospektif olması ve senkron lezyonları tespit edecek bir yöntem kullanılamamış olması ve hasta sağ kalımları hakkında bilgimizin olmamasıdır.

Özellikle rektosigmoid bölgede tespit edilen obstrükte kitle sayısı azımsanmayacak kadar fazladır. Ülkemiz şartlarında bu tür hastaların takip ve tedavisi için kullanılabilecek yöntemlerin sınırlı olduğu görülmektedir, ancak bununla birlikte BTK'nın özellikle senkron lezyonların yakalanması için preoperatif değerlendirmede uygun bir seçenek olduğu ve bu sayede mortalite ve morbidite üzerine pozitif yönde katkısı olabileceği düşüncesindeyiz. Bu tür hastaların prospektif olarak değerlendirilip, preoperatif senkron lezyon tespiti için önerilen tekniklerin yapıldığı ve hastaların sağ kalımlarının analiz edildiği çalışmalara ihtiyaç olduğu fikrindeyiz.

\section{“Tüm yazarlar herhangi bir çıkar çatışması olmadığını ka- bul ederler."}

13. Atsushi I, Mitsuyoshi O, Kazuya Y, et al. Long-term outcomes and prognostic factors of patients with obstructive colorectal cancer: A multicenter retrospective cohort study. World J Gastroenterol 2016;22:5237-45.

14. Kabaçam G, Bektaș M, Sarıoğlu M, et al. Colorectal cancer detection rate in the last two decades at an endoscopy center. Endoscopy Gastrointertinal 2009; 17:28-31

15. Kahi CJ, Boland CR, Dominitz JA, et al. Colonoscopy Surveillance after Colorectal Cancer Resection: Recommendations of the US Multi-Society Task Force on Colorectal Cancer. Am J Gastroenterol 2016;111:337-46.

16. Hassan C, Wysocki PT, Fuccio L. Endoscopic surveillance after surgical or endoscopic resection for colorectal cancer: European Society of Gastrointestinal Endoscopy (ESGE) and European Society of Digestive Oncology (ESDO) Guideline. Endoscopy 2019;51:C1.

17. Milsom JW, Shukla P. Should intraoperative colonos-copy play a role in the surveillance for colorectal cancer? Dis Colon Rectum 2011;54:504-

18. Levin B, Lieberman DA, McFarland B, et al. Screening and surveillance for the early detection of colorectal cancer and adenomatous polyps, 2008: a joint guideline from the American Cancer Society, the US Multi-Society Task Force on Colorectal Cancer, and the American College of Radiology. CA Cancer J Clin 2008;58:130-60.

19. Park SH, Lee JH, Lee SS, et al. CT colonography for detection and characterisation of synchronous proximal colonic lesions in patients with stenosing colorectal cancer. Gut 2012;61:1716-22

20. Kahi CJ, Boland CR, Dominitz JA, et al. Colonoscopy Surveillance After Colorectal Cancer Resection: Recommendations of the US Multi-Society Task Force on Colorectal Cancer. Gastroenterology 2016;150:758-68.

21. Spada C, Stoker J, Alarcon O, et al. Clinical indications for computed tomographic colonography: European Society of Gastrointestinal Endoscopy (ESGE) and European Society of Gastrointestinal and Abdominal Radiology (ESGAR) Guideline. Endoscopy 2014;46:897-915.

22. Suttie SA, Shaikh I, Mullen R, et al. Outcome of right- and left-sided colonic and rectal cancer following surgical resection. Colorectal Dis 2011;13:884-9. 